\title{
Activation of Hippocampal Nuclear Factor- $\kappa$ B by Retrieval Is Required for Memory Reconsolidation
}

\author{
Mariano Boccia, ${ }^{1 *}$ Ramiro Freudenthal, ${ }^{2 *}$ Mariano Blake, ${ }^{1}$ Veronica de la Fuente, ${ }^{2}$ Gabriela Acosta, ${ }^{3}$ Carlos Baratti, ${ }^{1}$ \\ and Arturo Romano ${ }^{2}$ \\ ${ }^{1}$ Laboratorio de Neurofarmacología de Procesos de Memoria, Cátedra de Farmacología, Facultad de Farmacia y Bioquímica, Universidad de Buenos Aires, \\ Buenos Aires, Argentina, ${ }^{2}$ Laboratorio de Neurobiología de la Memoria, Departamento de Fisiología, Biología Molecular y Celular, Facultad de Ciencias \\ Exactas y Naturales, Universidad de Buenos Aires, Instituto de Fisiología, Biología Molecular y Neurociencias, Consejo Nacional de Investigaciones \\ Científicas y Técnicas (CONICET), 1428 EHA Buenos Aires, Argentina, and '3nstituto de Investigaciones Farmacológicas-CONICET, 1113 Buenos Aires, \\ Argentina
}

Initially, memory is labile and requires consolidation to become stable. However, several studies support that consolidated memories can undergo a new period of lability after retrieval. The mechanistic differences of this process, termed reconsolidation, with the consolidation process are under debate, including the participation of hippocampus. Up to this point, few reports describe molecular changes and, in particular, transcription factor (TF) involvement in memory restabilization. Increasing evidence supports the participation of the TF nuclear factor $-\kappa \mathrm{B}(\mathrm{NF}-\kappa \mathrm{B})$ in memory consolidation. Here, we demonstrate that the inhibition of NF- $\kappa \mathrm{B}$ after memory reactivation impairs retention of a hippocampal-dependent inhibitory avoidance task in mice. We used two independent disruptive strategies to reach this conclusion. First, we administered intracerebroventricular or intrahippocampal sulfasalazine, an inhibitor of IKK (I $\kappa \mathrm{B}$ kinase), the kinase that activates NF- $\kappa$ B. Second, we infused intracerebroventricular or intrahippocampal $\kappa$ B decoy, a direct inhibitor of NF- $\kappa$ B consisting of a double-stranded DNA oligonucleotide that contains the $\kappa \mathrm{B}$ consensus sequence. When injected immediately after memory retrieval, sulfasalazine or $\kappa \mathrm{B}$ decoy (Decoy) impaired long-term retention. In contrast, a one base mutated $\kappa \mathrm{B}$ decoy (mDecoy) had no effect. Furthermore, we also found NF- $\kappa$ B activation in the hippocampus, with a peak 15 min after memory retrieval. This activation was earlier than that found during consolidation. Together, these results indicate that NF- $\kappa \mathrm{B}$ is an important transcriptional regulator in memory consolidation and reconsolidation in hippocampus, although the temporal kinetics of activation differs between the two processes.

Key words: reconsolidation; hippocampus; NF- $\kappa \mathrm{B} ; \kappa \mathrm{B}$ decoy; sulfasalazine; inhibitory avoidance

\section{Introduction}

The consolidation hypothesis states that, initially, memory is susceptible to disruption or facilitation but becomes stable and resistant to amnesic agents after a discrete period of time (McGaugh and Petrinovich, 1966; Davis and Squire, 1984). This concept was challenged by evidence that memory retrieval can open a new period of instability. During the retrieval period, memory requires consolidation-like mechanisms for its restabilization, a process named reconsolidation (Misanin et al., 1968; Mactutus et al., 1979; Nader et al., 2000; Sara, 2000; Pedreira et al., 2002; Boccia et al., 2004; Alberini, 2005). However, at present

Received March 10, 2007; revised 0ct. 18, 2007; accepted 0ct. 18, 2007.

This work was supported by Fondo para la Investigación Científica y Tecnológica Grants PICT 06041 and PICT 26095 (A.R.) and Grant B035 from the University of Buenos Aires (C.B.). We are indebted to Dr. Liliana Orelli and John Tuthill for language correction.

${ }^{*} M . B$. and R.F. contributed equally to this work.

Correspondence should be addressed to Arturo Romano, Laboratorio de Neurobiología de la Memoria, Departamento de Fisiología, Biología Molecular y Celular, Facultad de Ciencias Exactas y Naturales, Universidad de Buenos Aires, IFIBYNE/CONICET, Ciudad Universitaria, Pabellón II, 2do piso (C1428EHA), Buenos Aires, Argentina. E-mail: aromano@fbmc.fcen.uba.ar.

DOI:10.1523/JNEUROSCI.4430-07.2007

Copyright $\odot 2007$ Society for Neuroscience $\quad 0270-6474 / 07 / 2713436-10 \$ 15.00 / 0$ little is known about the molecular pathways involved in this process. The regulation of gene expression is critical for longlasting storage of memory. Therefore, a question arises: Has reconsolidation process similar requirement of gene expression and transcription factors (TFs)? The description of molecular mechanisms in postretrieval memory stabilization is important to accurately characterize reconsolidation and compare it with consolidation.

A number of TFs are involved in long-term memory (LTM) formation, including nuclear factor $-\kappa \mathrm{B}(\mathrm{NF}-\kappa \mathrm{B})$ (Romano et al., 2006). Some of them are also involved in memory reconsolidation, such as cAMP-response element binding protein (CREB) (Hall et al., 2001b), CCAAT/enhancer binding protein (C/EBP) (Taubenfeld et al., 2001), and zif268 (Hall et al., 2001a; Bozon et al., 2003). Recently, we described that NF- $\kappa \mathrm{B}$ is required for memory reconsolidation in invertebrates (Merlo et al., 2005).

Inactive $\mathrm{NF}-\kappa \mathrm{B}$ is present in the cytoplasm of neurons, bound to its inhibitor, I $\kappa \mathrm{B}$. I $\kappa \mathrm{B}$ occludes the nuclear localization sequence. In response to specific stimuli, such as NMDA receptor activation, $\mathrm{I} \kappa \mathrm{B}$ kinase (IKK) phosphorylates the inhibitor $\mathrm{I} \kappa \mathrm{B}$, allowing NF- $\kappa \mathrm{B}$ translocation to the nucleus. This process serves as a crucial step in the regulation of transcriptional activity 
(Ghosh and Karin, 2002). In a previous report, we found that $\mathrm{NF}-\kappa \mathrm{B}$ is required for memory consolidation in an inhibitory avoidance task in mice (Freudenthal et al., 2005). NF- $\kappa$ B was activated in hippocampus $45 \mathrm{~min}$ after training and its disruption caused memory impairment. NF- $\kappa$ B inhibition was achieved using two independent strategies. First, we administered a specific $\mathrm{I} \kappa \mathrm{B}$ kinase inhibitor, sulfasalazine. Second, we injected $\kappa \mathrm{B}$ decoy DNA oligonucleotide (Decoy), which impedes NF- $\kappa$ B binding to the consensus sequence in their normal sites of action. In this task, hemicholinium, an inhibitor of choline uptake, or the presentation of a new learning task, impaired memory consolidation and reconsolidation (Boccia et al., 2004, 2005, 2006).

The participation of the hippocampus in postretrieval memory processes is controversial. On the one hand, data support hippocampal involvement in both consolidation and reconsolidation (Debiec et al., 2002; Rossato et al., 2006), and, in contrast, data support that hippocampus is involved in consolidation but not in reconsolidation (Taubenfeld et al., 2001; Tronel et al., 2005).

Here, we used an inhibitory avoidance task in mice, in which $\mathrm{NF}-\kappa \mathrm{B}$ is involved in consolidation, to examine the potential role of this TF in hippocampus on memory restabilization after retrieval. For this purpose, we analyzed the effect of NF- $\kappa \mathrm{B}$ postretrieval inhibition and we studied the time course of NF- $\kappa \mathrm{B}$ activation after retrieval in hippocampus.

\section{Materials and Methods}

Animals. CF-1 male mice (FUNDACAL, Buenos Aires, Argentina; age, $60-70 \mathrm{~d}$; weight, $25-30 \mathrm{~g}$ ) were individually caged and singly housed throughout the experimental procedures. Mice were kept in a lodging room maintained at $21-23^{\circ} \mathrm{C}$ on a $12 \mathrm{~h}$ light/dark cycle (lights on at 6:00 A.M.), with ad libitum access to dry food and tap water. Experiments were performed in accordance with the National Institutes of Health (NIH) Guide for the Care and Use of Laboratory Animals (NIH publication 80-23/96) and local regulations. All efforts were made to minimize animal suffering and to reduce the number of animals used.

Apparatus and behavioral procedure. Inhibitory avoidance behavior was studied in a one-trial learning, step-through type situation (Boccia et al., 2004), which takes advantage of the natural preference of mice for a dark environment. The apparatus consisted of a dark compartment $(20 \times 20 \times 15 \mathrm{~cm})$ with a stainless-steel grid floor and an illuminated, elevated platform $(5 \times 5 \mathrm{~cm})$. Mice had no experience of the dark compartment before the learning trial. During training, each mouse was placed on the platform and received a footshock as it stepped into the dark compartment. The footshock-training conditions $(1.2 \mathrm{~mA} ; 50 \mathrm{~Hz}$; $1 \mathrm{~s}$ ) ensured a high latency even after several subsequent tests (Boccia et al., 2004). An initial retention test was performed $48 \mathrm{~h}$ after training. Each mouse was placed on the platform and the step-through latency was recorded. The retention test was finished either when the mouse stepped into the dark compartment or failed to cross within $300 \mathrm{~s}$. In the latter case, the mouse was immediately removed from the platform and assigned a score of $300 \mathrm{~s}$. In the testing session, the step-through latency was measured in the absence of a footshock. One, four, or five additional testing sessions with $24 \mathrm{~h}$ intervals were given, depending on the experiment. In one experiment, a second test was performed $3 \mathrm{~h}$ after the first test. In experiments in which we measured nuclear NF- $\kappa \mathrm{B}$ activity, animals were killed at distinct intervals after the first test.

Injections. Mice were prepared (Boccia et al., 2004) for either intracerebroventricular or intrahippocampal injections of vehicle or drug solutions $48 \mathrm{~h}$ before training. Injections were administered under light ether anesthesia in a stereotaxic instrument. The preliminary surgery was also performed under ether anesthesia and consisted of deflecting the scalp and drilling two symmetrical holes through the skull without puncturing the brain. The skull was covered with bone wax and the mouse was then returned to its home cage. For intracerebroventricular infusions, vehicle or drug solution was injected unilaterally randomly into either the left or right lateral ventricle at a volume of 1 or $1.7 \mu$, depending of the drug injected. The injection coordinates were anterior/posterior $(\mathrm{A} / \mathrm{P})(-0.34$ $\mathrm{mm}$ respect to bregma), left/right $(\mathrm{L} / \mathrm{R})(+1.00 \mathrm{~mm}$ to the right or left from the midsagittal suture), and ventral (V) $(-2.10 \mathrm{~mm}$ from a flat skull surface) (Franklin and Paxinos, 2001). Injections were performed during $90 \mathrm{~s}$ through a 30 gauge blunt stainless-steel needle attached to a $10 \mu \mathrm{l}$ Hamilton syringe with PE-10 tubing and driven by hand. Accuracy of the intracerebroventricular injection was $>90 \%$ as determined by methylene blue injections performed regularly and by fluoresceinated Decoy (data not shown). For dorsal intrahippocampal injections, vehicle or drug solution was bilaterally infused at the following stereotaxic coordinates: $\mathrm{A} / \mathrm{P}(-1.50 \mathrm{~mm}$ posterior to bregma), $\mathrm{L} / \mathrm{R}(+1.50 \mathrm{~mm}$ from the midsagittal suture), and $\mathrm{V}(-1.50 \mathrm{~mm}$, from a flat skull surface). Injections were performed during $90 \mathrm{~s}$ through a 30 gauge blunt stainless-steel needle attached to a $5 \mu \mathrm{l}$ Hamilton syringe with PE-10 tubing and driven by hand. The volume of each intrahippocampal infusion was $0.5 \mu$ l. For the control injection in a different area, the primary somatosensory cortex, forelimb region was chosen. Control injections were applied at the following stereotaxic coordinates: A/P (0.62 mm anterior to bregma), L/R $(+2.50 \mathrm{~mm}$ from the midsagittal suture), and $\mathrm{V}(-1.50 \mathrm{~mm})$.

The accuracy of intrahippocampal injection was determined by fluoresceinated Decoy (see Fig. $8 \mathrm{~A}$ ) and by histological determination of the needle position on an animal-by-animal basis (see Fig. $8 B$ ).

Distribution analysis of fluoresceinated Decoy in the hippocampus and histological determination of the needle position after intrahippocampal injections. Injected animals were killed at different times to evaluate the distribution of the fluoresceinated DNA oligonucleotide in the brain. The brains were dissected and cut in $25 \mu \mathrm{m}$ coronal sections. To better visualize the localization of the Decoy, the brains were counterstained with propidium iodide. The double-stained sections were visualized with a confocal microscope. To determine the needle position, the brains of injected animals were dissected, fixed in $4 \%$ paraformaldehyde/buffer phosphate saline, and stored in $30 \%$ sucrose. They were then cut into 25 $\mu \mathrm{m}$ coronal sections with a cryostat. The deepest position of the needle was superimposed on serial coronal maps (Franklin and Paxinos, 2001). Coronal sections containing the deepest reach of the needle were Nissl stained to estimate the damage produced during the procedure (see Fig. $8 B)$.

Drugs. 2-4-Hydroxy((4-((2-pyridinilamino)sulfonyl)phenyl)azo)benzoic acid (sulfasalazine) (Sigma, St. Louis, MO) and 1-(4chlorobenzoyl)-5-methoxy-2-methyl- $1 \mathrm{H}$-indole-3-acetic acid (indomethacin) were injected in a saline solution containing 10 mM HEPES, $\mathrm{pH}$ 7.6, and 1\% DMSO.

Decoy (5'-GAGGGGACTTTCCCA-3'; consensus sequence in bold) and mDecoy (5'-GAGGCGACTTTCCCA-3'; base changed underlined) were dissolved in TE saline solution.

Sulfasalazine ( 3 and $7 \mathrm{~mm}$ ) and indomethacin (166 and $500 \mu \mathrm{M}$ ) were administered intracerebroventricularly at a volume of $1 \mu \mathrm{l}$. Decoy and mDecoy $(36.6 \mu \mathrm{g} / \mu \mathrm{l})$ were administered intracerebroventricularly at a volume of $1.7 \mu$ l, delivering $12.5 \mathrm{nmol}$. In the hippocampus, the drugs were administered bilaterally at a volume of $0.5 \mu$ l. Decoy or mDecoy were used at a concentration of $1.46 \mu \mathrm{g} / \mu \mathrm{l}$, delivering $0.15 \mathrm{nmol}$ per hippocampus. Sulfasalazine was used at concentrations of $0.5 \mathrm{~mm}(0.2 \mu \mathrm{g}$ per hippocampus), $1.25 \mathrm{~mm}$ (0.5 $\mu \mathrm{g}$ per hippocampus), and $2.5 \mathrm{~mm}$ (1.0 $\mu \mathrm{g}$ per hippocampus), and indomethacin was used at concentrations of $0.363 \mathrm{~mm}$ (13 ng per animal) and $1.816 \mathrm{~mm}$ (65 ng per animal).

Nuclear extracts and determination of DNA-binding activity by gel shift. Mice were killed by cervical dislocation at different intervals after testing (see Results). Brains were rapidly removed, and both hippocampi were dissected according to the method of Glowinski and Iversen (1966). To obtain nuclear extracts, tissues were homogenized in $250 \mu \mathrm{l}$ of buffer A (10 mм HEPES, pH 7.9, 10 mu KCl, 1.5 mm $\mathrm{MgCl}_{2}, 1 \mathrm{~mm}$ DTT, $1 \mu \mathrm{g} / \mathrm{ml}$ pepstatin $\mathrm{A}, 10 \mu \mathrm{g} / \mathrm{ml}$ leupeptin, $0.5 \mathrm{~mm}$ PMSF, and $10 \mu \mathrm{g} / \mathrm{ml}$ aprotinin) with eight strokes in a Dounce homogenizer, type B pestle. The homogenate was centrifuged for $15 \mathrm{~min}$ at $1000 \times \mathrm{g}$, the pellet was resuspended in $30 \mu$ l of buffer B (20 mm HEPES, pH 7.9, $1.2 \mathrm{M} \mathrm{KCl,} 1.5 \mathrm{~mm} \mathrm{MgCl}_{2}, 0.4$ mм EDTA, $0.5 \mathrm{~mm}$ DTT, $50 \%$ glycerol, $1 \mu \mathrm{g} / \mathrm{ml}$ pepstatin A, $10 \mu \mathrm{g} / \mathrm{ml}$ leupeptin, $0.5 \mathrm{~mm}$ PMSF, and $10 \mu \mathrm{g} / \mathrm{ml}$ aprotinin) and incubated for 15 $\min$ on ice. A centrifugation for $15 \mathrm{~min}$ at $12,000 \times g$ was then per- 
A
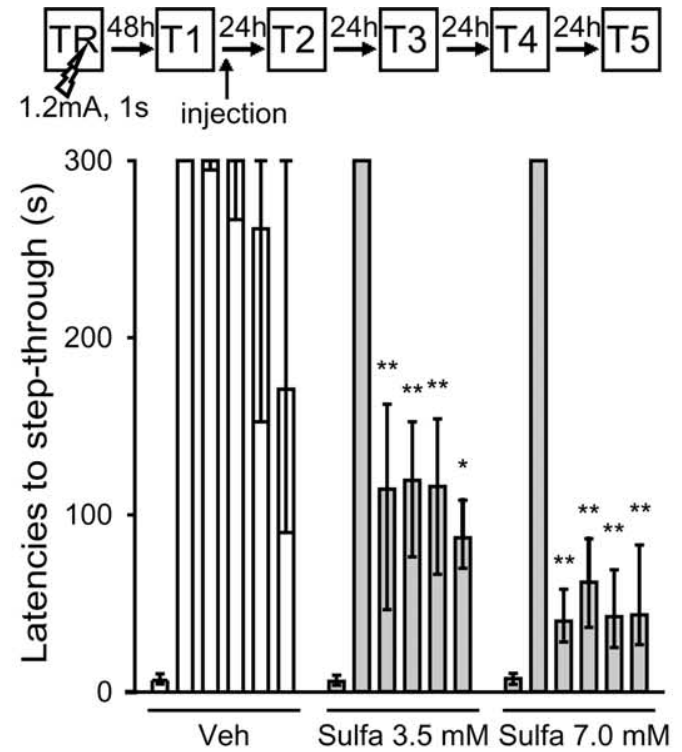

B

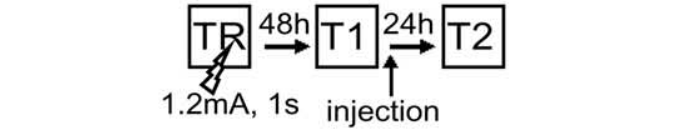

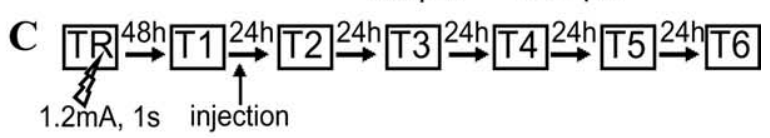

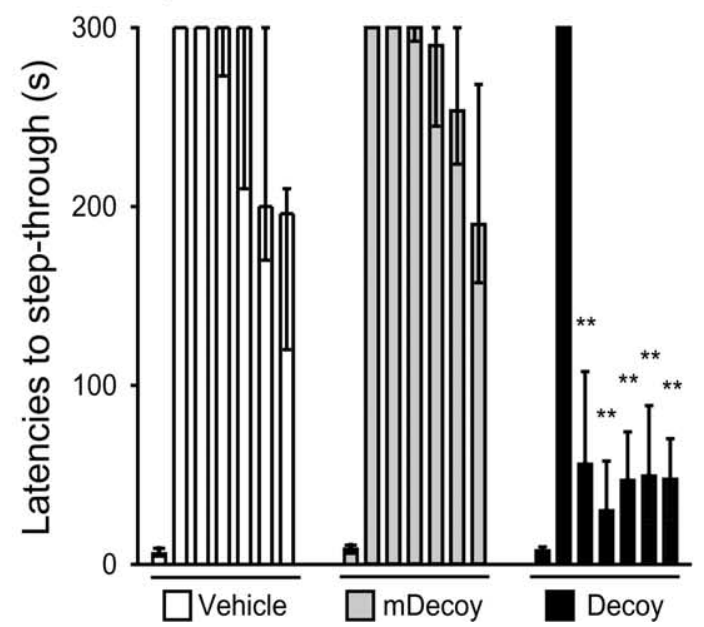

Figure 1. Effect of intracerebroventricular administration of NF- $\kappa$ B inhibitors after reexposure to the training context. $A$, Effect of the IKK inhibitor sulfasalazine. Top diagram, Design of the experiment. TR, Training with a footshock; T1, reactivation session; T2-T5, successive test-

formed. The supernatant was kept at $-70^{\circ} \mathrm{C}$ until used. The entire extraction protocol was performed at $4^{\circ} \mathrm{C} . \kappa \mathrm{B}$-like DNA binding activity in nuclear fractions was assessed using gel shift [electrophoretic mobility shift assay (EMSA)]. An aliquot of 1.75 pmol of double-stranded oligonucleotide DNA containing the NF- $\kappa \mathrm{B}$ binding site $\left(5^{\prime}-\right.$ AGTTGAGGGGACTTTCCCAGGC-3' ${ }^{\prime}$, binding site in bold) (Promega, Madison, WI) was labeled at $37^{\circ} \mathrm{C}$ for $10 \mathrm{~min}$ in $10 \mu \mathrm{l}$ of reaction buffer containing $70 \mathrm{~mm}$ Tris- $\mathrm{HCl}, 10 \mathrm{~mm} \mathrm{MgCl}_{2}, 5 \mathrm{~mm}$ DTT, $15 \mu \mathrm{Ci}$ of $\left[\gamma-\mathrm{P}^{32}\right]$ ATP (DuPont NEN, Wilmington, DE) and $10 \mathrm{U}$ of T4 polynucleotide kinase (Promega). DNA-protein binding was performed in 20 $\mu \mathrm{l}$ containing $20 \mathrm{~mm}$ HEPES, pH 7.9, $120 \mathrm{~mm} \mathrm{KCl,} 0.4$ mм EDTA, $0.5 \mathrm{~mm}$ DTT, $25 \%$ glycerol, and $10 \mu \mathrm{g}$ of protein extract. Samples were incubated for $30 \mathrm{~min}$ at $0^{\circ} \mathrm{C}$ and $1 \mathrm{ng}$ of labeled oligonucleotide DNA probe was added followed by incubation for another $30 \mathrm{~min}$ at $0^{\circ} \mathrm{C}$. The reaction mixture was then electrophoresed on a $6 \%$ non-denaturing polyacrylamide gel in $0.25 \times$ TBE $(22.3 \mathrm{~mm}$ Tris, $22.3 \mathrm{~mm}$ boric acid, $0.5 \mathrm{~mm}$ EDTA) for $2 \mathrm{~h}$ at $150 \mathrm{~V}$. The gel was vacuum-dried and exposed overnight to XAR-5 film (Kodak, Rochester, NY). Using this probe, three specific retarded bands are identifiable (Freudenthal et al., 2004). The relative optical density (ROD) of the first band corresponding to p65/p50 heterodimer was estimated using NIH Image J 1.29 X software. All measures were made with exposures within the linear range of the film. Images were digitized by means of a transmissive scanner (Umax PowerLook III). Protein contents of the extracts were measured in triplicate by Bradford method and checked for quality and quantity by comparing pattern intensities in SDS-PAGE.

Data analysis. The latencies to step-through, either during training or retention test, were expressed as medians and interquartile ranges, and were analyzed with Kruskal-Wallis nonparametric ANOVA. Differences between groups were estimated by individual Mann-Whitney $U$ tests (two-tailed) (Siegel, 1956), considering values of $p<0.05$ as significant. Training step-through latencies differences among all the groups used in these experiments were not significant.

For the experiments designed to estimate NF- $\kappa$ B activity in hippocampus, ROD values for each group were relativized to the mean ROD values of a naive $(\mathrm{N})$ group, which consisted in untreated animals. General ANOVA and Duncan's test were used to estimate differences between $\mathrm{N}$ and the other groups. In some cases for variance homogeneity and normality, data were transformed to $(\log +1)$ before the statistical analysis.

\section{Results}

The intracerebroventricular administration of NF- $\kappa \mathrm{B}$ inhibitors impairs memory when administered shortly after retrieval

The first part of this work was aimed at evaluating whether retention can be affected by NF- $\kappa \mathrm{B}$ inhibition after memory reactivation induced by a first testing $48 \mathrm{~h}$ after a one trial training. In the first experiment, we administered after testing either vehicle or the IKK inhibitor sulfasalazine by intracerebroventricular injection. We evaluated two doses, one of them, $7 \mathrm{~mm}$, effectively impaired memory when injected after training, and the other, 3 $\mathrm{mM}$, was insufficient after training for memory impairment

\footnotetext{
$\leftarrow$

ing sessions with $24 \mathrm{~h}$ intervals; the injections were performed immediately after T1 (memory reactivation). The graph represents the latencies to step-through expressed as medians and interquartile ranges of animals injected with vehicle $(N=10), 3.5 \mathrm{~mm}(N=10)$, or $7 \mathrm{~mm}$ sulfasalazine (Sulfa) $(N=12) .{ }^{* *} p<0.01 ;{ }^{*} p<0.05$ when compared with its respective test session of the vehicle-treated group (Mann-Whitney $U$ test, two-tailed). $\boldsymbol{B}$, Effect of indomethacin. Top diagram, Design of the experiment. The injections were performed immediately after $\mathrm{T} 1$ (memory reactivation). The graph is as in $\boldsymbol{A} . N=10$ for each group. $C$, Effect of Decoy. Top diagram, Design of the experiment. TR, Training with a footshock; T1, reactivation session; $\mathrm{T} 2-\mathrm{T} 6$, successive testing sessions with $24 \mathrm{~h}$ intervals; the injections were performed immediately after reactivation. Each bar represents the medians and interquartile ranges. Mice were injected either with vehicle $(N=7)$, mDecoy $(N=8)$, or Decoy $(N=12)$. ${ }^{* *} p<0.01$ compared with its respective test session of the vehicle and mDecoy-treated groups (Mann-Whitney $U$ test, two-tailed).
} 
(Freudenthal et al., 2005). The first test before drug administration showed good retention for all groups. Four subsequent tests were presented with an interval of $24 \mathrm{~h}$ (Fig. $1 \mathrm{~A}$, top diagram). Both sulfasalazine doses provoked retention impairment in the four testing sessions (Fig. 1A) showing significant differences with the respective vehicle group. Sulfasalazine was developed as an antiinflammatory drug and its action was originally attributed to the inhibition of cyclooxygenase (COX) until its action as IKK inhibitor was described (Weber et al., 2000). The following experiment was aimed at evaluating whether the amnesic effect of sulfasalazine could be explained as a potential effect on COX. For this purpose, we used indomethacin, a COX and prostaglandin inhibitor that does not interfere with the NF- $\kappa \mathrm{B}$ pathway (Yin et al., 1998). Two doses were evaluated, 166 and $500 \mu \mathrm{M}$, as in previous work (Freudenthal et al., 2005). Higher doses were not used to avoid nonspecific effects on behavior (Merlo et al., 2002). No effect of this drug was found when injected after test 1 and evaluated $24 \mathrm{~h}$ later in test 2 (Fig. $1 \mathrm{~B}$ ), indicating that indomethacin did not induce retention impairment in the examined doses. This absence of effect was also observed when indomethacin was administered intracerebroventricularly immediately after training (Freudenthal et al., 2005).

Next, instead of the upstream step inhibition used in the first experiments, we performed a direct inhibition of NF- $\kappa \mathrm{B}$ using double-stranded DNA oligonucleotide containing the $\kappa \mathrm{B}$ consensus sequence (Decoy). In a previous work, Decoy was effective when administered intracerebroventricularly to inhibit NF- $\kappa \mathrm{B}$ in hippocampus and to impair long-term memory when injected $2 \mathrm{~h}$ before training (Freudenthal et al., 2005). In contrast, administration of a Decoy containing only a one base mutation, but conserving the overall composition of bases (mDecoy), did not produce NF- $\kappa \mathrm{B}$ inhibition and memory impairment. This mutation impedes the transcription factor recognition of the consensus sequence.

Initially, we performed intracerebroventricular injection of fluoresceinated Decoy, and 15 min after injection the presence of fluorescence in hippocampal neurons was corroborated by confocal microscopy (data not shown). Next, we administered saline, Decoy, or mDecoy immediately after test 1 , and we evaluated their effect in five subsequent tests with $24 \mathrm{~h}$ intervals. As shown in Figure $1 C$, only $\kappa \mathrm{B}$ decoy impaired retention in all subsequent tests, showing significant differences with saline and mutated $\kappa \mathrm{B}$ decoy.

\section{The inhibition of NF- $\kappa \mathrm{B}$ in hippocampus shortly after retrieval impairs memory}

In the following experiments, we performed dorsal intrahippocampal administration of NF- $\kappa \mathrm{B}$-inhibiting drugs to investigate involvement of hippocampal NF- $\kappa \mathrm{B}$ in memory reconsolidation. In the first experiment, we administered the vehicle injection or the IKK inhibitor sulfasalazine $(0.2,0.5$, and $1.0 \mu \mathrm{g}$ per hippocampus) after test 1 (T1). The lower dose of sulfasalazine was chosen based on intracerebroventricular administration experiments and the mass relationship between hippocampus and whole brain. During the first retention test (T1), $48 \mathrm{~h}$ after training, all mice exhibited maximal retention latencies. The subsequent test was presented with an interval of $24 \mathrm{~h}$ (Fig. $2 \mathrm{~A}$, top diagram). In this case, the higher two doses of sulfasalazine, but not the lower dose, impaired retention [for T2, Veh vs $0.2 \mu \mathrm{g}$, nonsignificant; Veh $(n=12)$ vs $0.5 \mu \mathrm{g}(n=12), U=144, p<$ 0.01; Veh vs $1 \mu \mathrm{g}(n=11), U=132, p<0.01$ ] (Fig. $2 A)$. This result suggests that sulfasalazine acts in a dose-dependent manner.
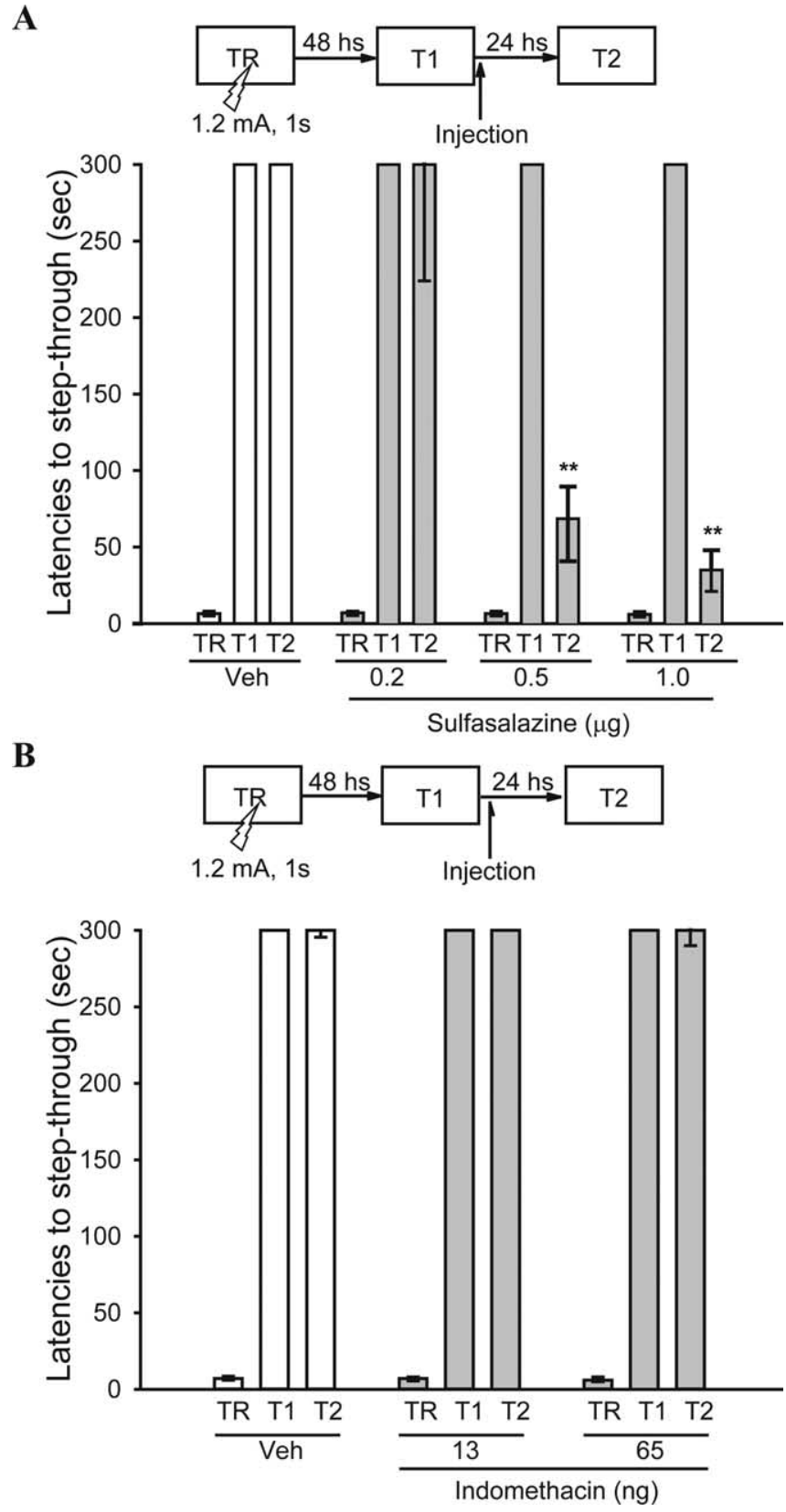

Figure 2. Effect of the IKK inhibitor sulfasalazine when injected intrahippocampally after reexposure to the training context. $\boldsymbol{A}$, Top diagram, Design of the experiment. TR, Training with a footshock; $\mathrm{T} 1$, reactivation session; $\mathrm{T} 2$ testing sessions after $24 \mathrm{~h}$ interval; the injections were performed immediately after $\mathrm{T} 1$ (memory reactivation). The graph represents the latencies to step-through expressed as medians and interquartile ranges of animals injected with vehicle $(N=12), 0.2 \mu \mathrm{g}(N=8), 0.5 \mu \mathrm{g}(N=12)$, or $1 \mu \mathrm{g}(N=11)$ of sulfasalazine (Sulfa). ${ }^{* *} p<$ 0.01 , when compared with its respective test session of the vehicle-treated group (MannWhitney $U$ test, two-tailed). $\boldsymbol{B}$, Effect of indomethacin injection after reexposure. Top diagram, Design of the experiment. The injections were performed immediately after T1 (memory reactivation). The graph is as in $\boldsymbol{A}$. Two doses of indomethacin, 13 or $65 \mathrm{ng}$ per hippocampus, were administrated. $N=10$ for each group.

Based on previous experiments using intracerebroventricular administration and considering the hippocampal mass, two doses of indomethacin, 13 or $65 \mathrm{ng}$ per hippocampus, were administrated. We found no effect of this drug when injected immediately after T1 and evaluated $24 \mathrm{~h}$ later in T2 (Fig. 2 B), indicating that indomethacin did not cause retention impairment in the examined doses. 
A

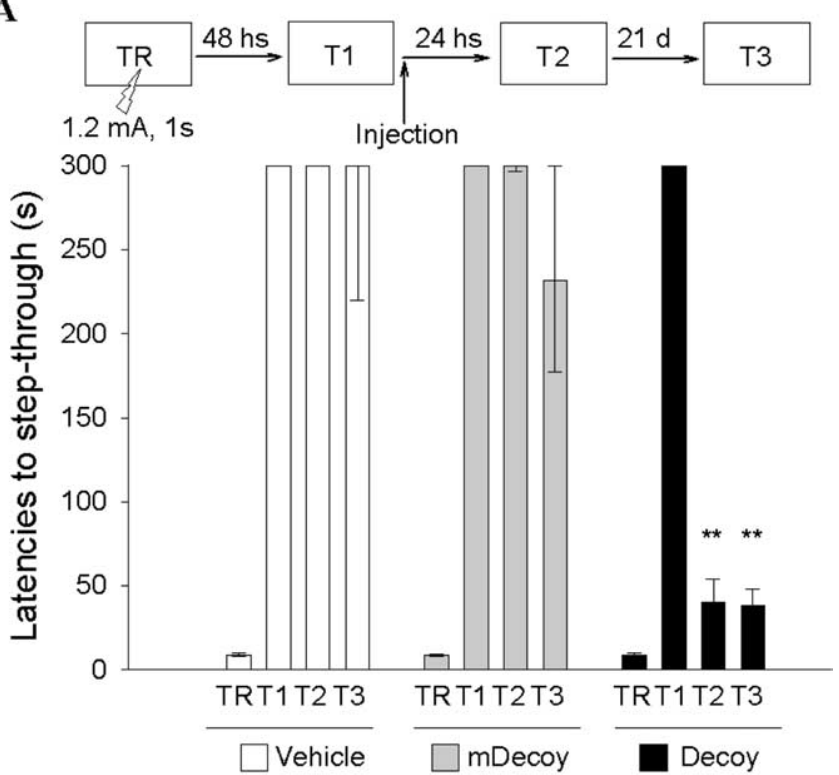

B

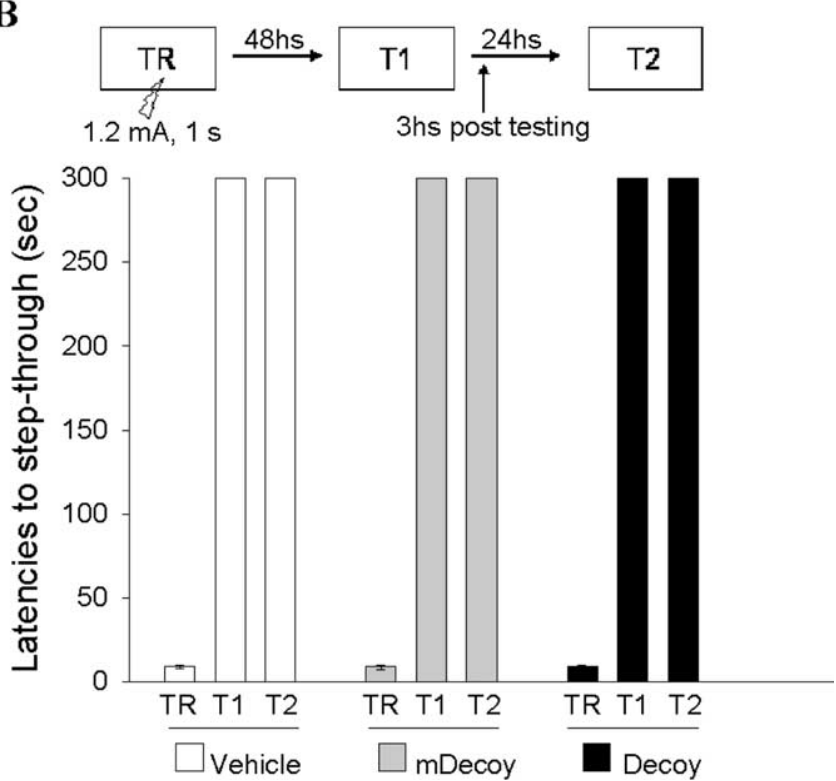

Figure 3. Effect of Decoy in hippocampus after reexposure to the training context. $A$, Decoy administered immediately after reexposure. Top diagram, Design of the experiment. TR, Training with a footshock; T1, reactivation session; $\mathrm{T} 2$ and $\mathrm{T} 3$, successive testing sessions with $24 \mathrm{~h}$ intervals; the injections were performed immediately after reactivation. Graph, Each bar represents the medians and interquartile ranges. Mice were injected either with vehicle $(N=7)$, mDecoy $(N=7)$, or Decoy $(N=7) .{ }^{* *} p<0.01$ compared with its respective test session of the vehicle and mDecoy-treated groups (Mann-Whitney $U$ test, two-tailed). $\boldsymbol{B}$, Effect of Decoy administered $3 \mathrm{~h}$ after reexposure. Top diagram, Design of the experiment. The graph is as in $\boldsymbol{A}$. $N=10$ for each group.

In the following experiments, three groups of mice were trained, and $48 \mathrm{~h}$ later, they were submitted to the first retention test. Immediately afterward, they received intrahippocampal infusions of either vehicle, mDecoy or Decoy. Two subsequent tests were performed at $24 \mathrm{~h}$ and $21 \mathrm{~d}$ after T1 (Fig. 3A, top diagram). As shown in Figure $2 A$, only Decoy impaired retention in the subsequent tests, showing significant differences with vehicle and mDecoy [for T2, Veh vs mDecoy treatment, nonsignificant, and Veh $(n=7)$ vs Decoy $(n=7), U=49, p<0.01$; for T3, Veh vs mDecoy, nonsignificant, and Veh $(n=7)$ vs Decoy $(n=7), U=$
A

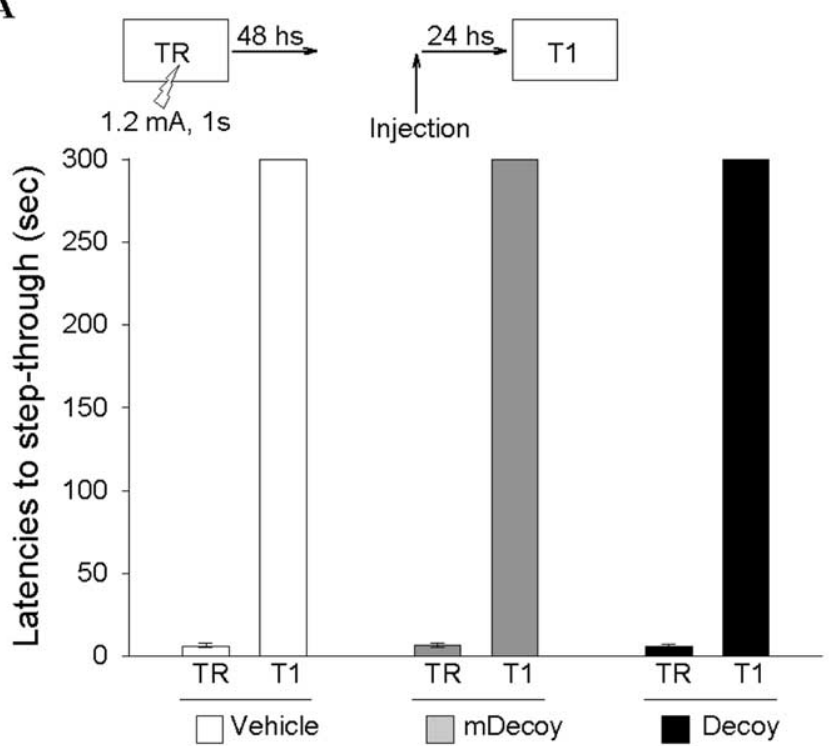

B
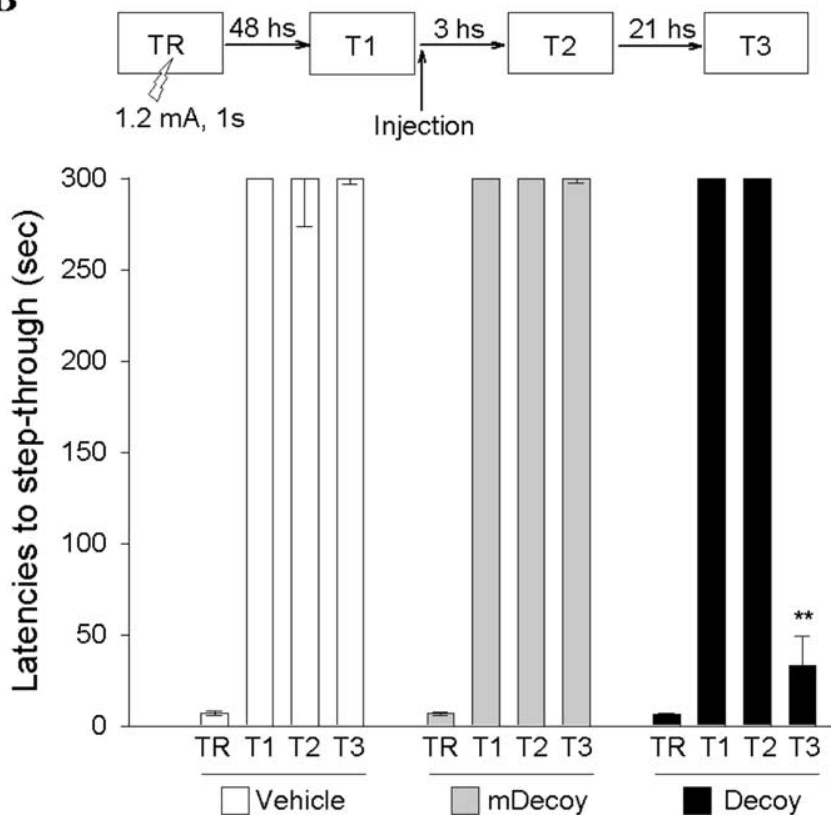

Figure 4. A, Effect of Decoy in hippocampus without reexposure to the training context. Top diagram, Design of the experiment. Graph, Each bar represents the medians and interquartile ranges. Mice were injected either with vehicle $(N=7), \mathrm{mDecoy}(N=7)$, or Decoy $(N=7)$. $\boldsymbol{B}$, Effect of Decoy administered after reexposure on short-term reactivated memory. Top diagram, Design of the experiment. Animals were tested (T2) $3 \mathrm{~h}$ after injection and retested $24 \mathrm{~h}$ after injection. The graph is as in $\boldsymbol{A} . N=8$ for each group. ${ }^{* *} p<0.01$ compared with its respective test session of the vehicle and mDecoy-treated groups (Mann-Whitney $U$ test, two-tailed).

$49, p<0.01]$. To determine whether the reactivated memory shows a time window of susceptibility to NF- $\kappa \mathrm{B}$ inhibition, the injection was delayed $3 \mathrm{~h}$ after the end of the first test (T1) and retention performance was again evaluated $24 \mathrm{~h}$ afterward (Fig. $3 B$, top diagram). Under these experimental conditions, no effect of Decoy on memory performance was observed (Fig. 3B).

In the next experiment, two groups of mice were injected with either, vehicle, mDecoy or Decoy $48 \mathrm{~h}$ after training, but did not experience the reactivation session (Fig. $4 A$, top diagram). In these experimental conditions, mice injected with Decoy performed as well as the vehicle-treated group at day 3 after training (Fig. 4A). 
A

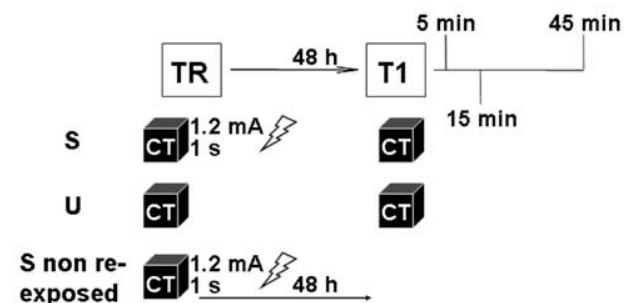

B

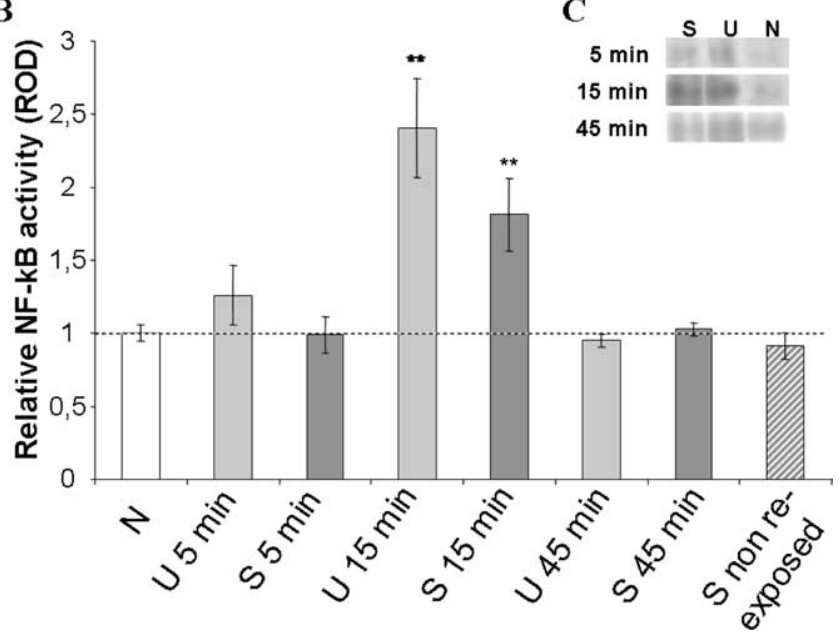

Figure 5. Temporal course of NF- $\kappa B$ activity after memory reactivation. $A$, Design of the experiment for shocked (S) and unshocked (U) groups. Animals were killed 5, 15, or 45 min after $\mathrm{T} 1$ or $48 \mathrm{~h}$ after training (S non-reexposed group). $\boldsymbol{B}, \mathrm{NF}-\kappa \mathrm{B}$ activity relative to the naive $(\mathrm{N})$ mean value estimated by densitometric analysis (ROD) of the p65/p50 EMSA band, obtained with hippocampal nuclear extracts from animals of the different groups. General ANOVA, $F_{(8,87)}$ $=8.94, p<0.01$. Duncan's test, N versus Sor $U, p<0.01$. C, Representative EMSAs of the three groups $(\mathrm{N}, \mathrm{U}$, and $\mathrm{S})$ for the different time points analyzed. $N=10$ for each group.

These results, together with those of the previous section, support that NF- $\kappa \mathrm{B}$ inhibition impairs memory reconsolidation. However, to demonstrate a specific action of the treatment in reconsolidation, it is critical to find intact post-reactivation short-term memory (STM) and impaired post-reactivation longterm memory. With this in mind, three additional groups of mice were trained on the inhibitory avoidance task and $48 \mathrm{~h}$ later they received either vehicle, mDecoy or Decoy immediately after T1. Three and $24 \mathrm{~h}$ later, they were submitted to two additional tests (Fig. $4 B$, top diagram). Post-reactivation STM was found intact in all groups. As in the previous experiment, only Decoy-injected animals showed LTM impairment (Fig. 4B) [for T2, Veh $(n=8)$ vs Decoy $(n=8), U=64, p<0.01]$.

Memory reactivation induces NF- $\kappa \mathrm{B}$ activity in hippocampus Our results thus far indicate that NF- $\kappa \mathrm{B}$ activity is required in hippocampus for memory reconsolidation. In the present section, we studied whether NF- $\kappa \mathrm{B}$ is activated in hippocampus by retrieval. In previous work, we found that NF- $\kappa \mathrm{B}$ is activated in hippocampus after training in this task (Freudenthal et al., 2005). In the first experiment of this section, one group of animals was trained with footshock in the chamber (S group), and another group received the same treatment without the shock (U group). Forty-eight hours after training, animals were tested and killed at 5,15 , or $45 \mathrm{~min}$. At this point, the hippocampus was removed. Another shocked group did not receive the testing session, and then was killed $48 \mathrm{~h}$ after training (S non-reexposed) (Fig. 5A). A naive $(\mathrm{N})$ group was included to determine the baseline of NF- $\kappa \mathrm{B}$ activity. We obtained nuclear extracts from each hippocampus and gel shift assay was used to estimate NF- $\kappa \mathrm{B}$ activity. We performed densitometric analysis of one of the two specific complexes observed in gel shift, corresponding to p65/p50 dimer of $\mathrm{NF}-\kappa \mathrm{B}$. We found an increase $15 \mathrm{~min}$ after testing in both $\mathrm{S}$ and $\mathrm{U}$ groups (general ANOVA, $F_{(8,87)}=8.94, p<0.01$; Duncan for $\mathrm{S}$ and $\mathrm{U}$ vs $\mathrm{N}, 15 \mathrm{~min}$ after reexposure, $p<0.01$ ) that returned to basal levels at $45 \mathrm{~min}$ (Fig. $5 \mathrm{~B}, \mathrm{C}$ ). It is important to note that this increase was not observed in the $S$ non-reexposed group, which was not reexposed and was killed together with the rest of the groups $48 \mathrm{~h}$ after training. This indicates that memory retrieval is required for the observed activation.

As in consolidation, the reconsolidation profiles of NF- $\kappa \mathrm{B}$ activation of $S$ and $U$ groups were very similar. One interpretation of this observation is that activation of NF- $\kappa \mathrm{B}$ in hippocampus during consolidation and reconsolidation is not specific to the association between conditioned stimulus (CS) and unconditioned stimulus (US). NF- $\kappa \mathrm{B}$ activation may be specific only to the codification of the contextual and spatial information of the CS, which will then be linked to US (footshock) information in other brain areas such as amygdala and neocortex (Fanselow and Gale, 2003). The memory effects observed after NF- $\kappa$ B inhibition in both consolidation and reconsolidation may be partially attributed to a disruption of neural plasticity mechanisms required for long-term CS representation in the hippocampus. However, the possibility that both the CS information and the CS-US linking are being processed in the hippocampus cannot be rejected $a$ priori for both consolidation and reconsolidation. Neural plasticity in the hippocampus could be responsible for the storage of contextual information in the U group, as well as the CS-US linking representation in the $\mathrm{S}$ group.

\section{Characterization of NF- $\kappa \mathrm{B}$ activation in hippocampus after CS-US association and context exposition}

The results of the previous section lead to two alternative explanations about hippocampal involvement in inhibitory avoidance and the role of NF- $\kappa \mathrm{B}$ in hippocampal processing. Precise characterization of the stimulus processing that induces NF- $\kappa \mathrm{B}$ activation in hippocampus after training is important to understand the mechanisms that determine memory consolidation. It is also important to understand the mechanisms recruited in retrieval of this information. With this in mind, we performed two experiments to evaluate alternative interpretations. We asked the following: Is NF- $\kappa \mathrm{B}$ activated only for storage of a new context representation or also for context-shock association storage? In the first experiment, two groups of mice were placed on the illuminated training platform and received no footshock as they stepped in the dark compartment. This procedure was repeated for 6 consecutive days. On the seventh day, one group of mice received the footshock when they entered in the dark compartment (S group). In the other group, the footshock was omitted (U group). These mice were killed $45 \mathrm{~min}$ later, the window after training in which NF- $\kappa \mathrm{B}$ is activated (Freudenthal et al., 2005). A third group of naive mice was included (N group) (Fig. 6A). The rationale for this experiment was that neural plasticity, and thus $\mathrm{NF}-\kappa \mathrm{B}$ activation, should not be required for contextual representation. This information should have already been consolidated during the previous trials. NF- $\kappa \mathrm{B}$ activation in hippocampus $45 \mathrm{~min}$ after training would indicate neural plasticity processes for CS-US storage. The densitometric analysis of the p65/p50 band of gel shift performed with hippocampal nuclear extracts from all groups revealed NF- $\kappa \mathrm{B}$ activation in the $\mathrm{S}$ group but not in the U group (general ANOVA, $F_{(2,24)}=7.7, p<0.01$; Duncan's test, $\mathrm{S}$ vs $\mathrm{N}, p<0.05$; $\mathrm{S}$ vs $\mathrm{U}, p<0.01$; U vs N, $p>0.05$ ) 
A

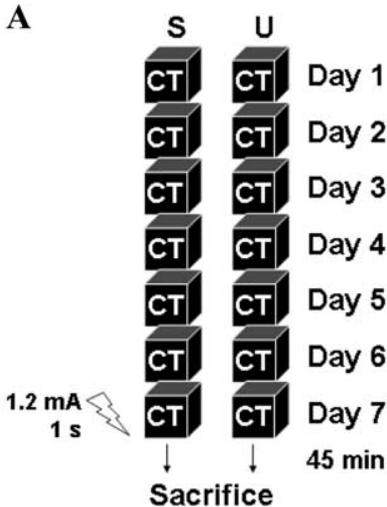

C

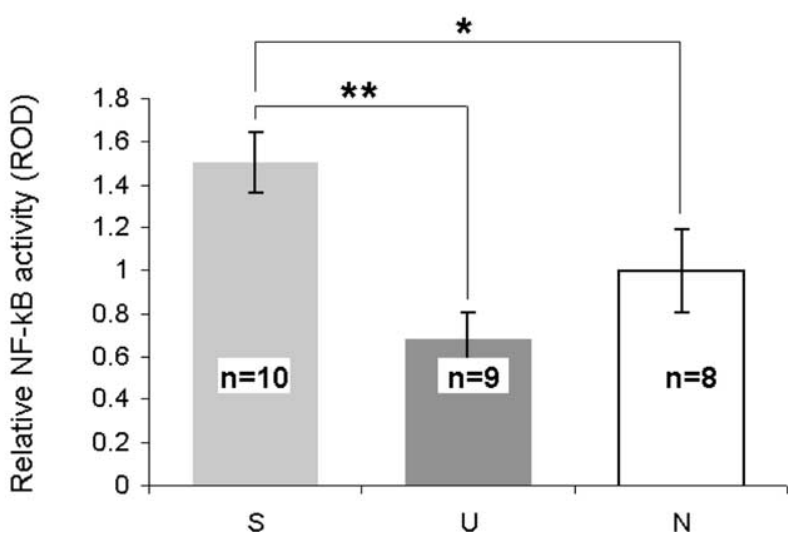

Figure 6. NF- $\kappa$ B activity after training when animals were preexposed to the context. $A$, Design of the experiment. Animals were killed $45 \mathrm{~min}$ after training. S group, Mice reexposed to the context for $6 \mathrm{~d}$ and shocked in the context at day 7. $\mathrm{U}$ group, Mice reexposed to the context for $7 \mathrm{~d}$. N, Untreated naive mice. $\boldsymbol{B}$, Representative EMSAs of the three groups. The arrowheads indicate specific bands. The black arrow indicates the complex measured. $\boldsymbol{C}, \mathrm{NF}-\kappa \mathrm{B}$ activity relative to the mean value of $\mathrm{N}$ group for the three groups, $45 \mathrm{~min}$ after the last trial. General ANOVA, $p<0.01$; Duncan's test, S versus $\mathrm{N}, p<0.05$; $\mathrm{S}$ versus $\mathrm{U}, p<0.01$; U versus $\mathrm{N}, p>$ 0.05 . ${ }^{* *} p<0.01$ and ${ }^{*} p<0.05$. $N$ of each group is indicated in the respective bar.

(Fig. $6 B, C$ ). This result indicates that context memory is already formed after repeated experience with an original environment. Therefore, NF- $\kappa \mathrm{B}$-mediated neural plasticity is not further required. The NF- $\kappa \mathrm{B}$ activation in the $\mathrm{S}$ group can be attributed to the plasticity required to associate the context (CS) with the foot shock (US). However, NF- $\kappa \mathrm{B}$ activation in the $\mathrm{S}$ group can also be interpreted as an unspecific response to a novel and stressful stimulus, the footshock. To evaluate this alternative hypothesis, we performed a second experiment in which one group of animals [the contingency group (CG)] becomes familiar with the context for $20 \mathrm{~s}$. Three hours later, the animals received the footshock in a new context. For the new context, mice were placed in a Plexiglas wall box $(20 \times 20 \times 10 \mathrm{~cm})$ located in a different room, brightly lit, with a stainless-steel grid floor. Mice remained in the new context only $1 \mathrm{~s}$ before being shocked and then were immediately removed. Under these conditions, the association between this context and footshock is not established, a phenomenon known as immediate shock deficit (Blanchard et al., 1976; Fanselow, 1986, 1990; Landeira-Fernandez et al., 2006). This procedure was repeated during $6 \mathrm{~d}$. On the seventh day, animals received the shock in the training chamber and were killed $45 \mathrm{~min}$ later (Fig. 6A). A second group, the iteration control group (ICG), was exposed each day during $7 \mathrm{~d}$ to the training context and $3 \mathrm{~h}$ later to the footshock in the new context. Animals were
A
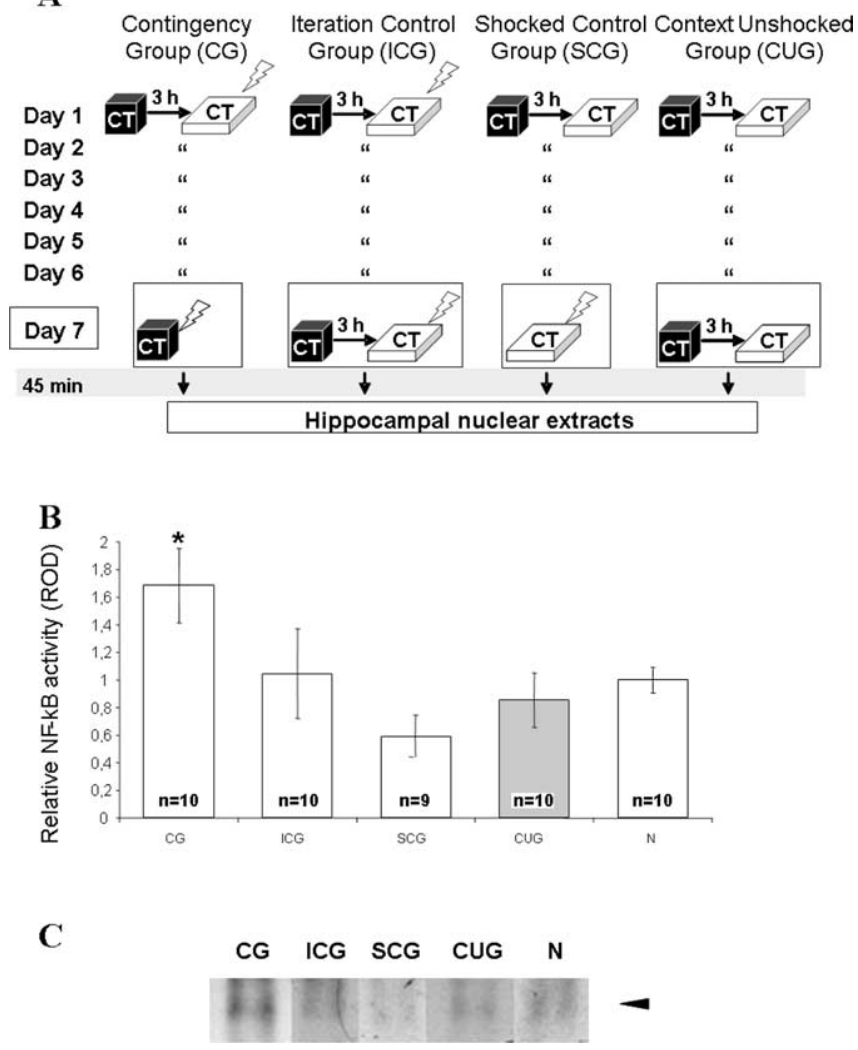

Figure 7. CS-US association activates NF- $\kappa B$ in hippocampus. $A$, Design of the experiment. Animals were killed $45 \mathrm{~min}$ after the last training or exposure. $\boldsymbol{B}$, Densitometric analysis of the p65/p50 retarded band. $C$, Representative retarded bands obtained in gel shift for each group; the black arrowhead indicates the quantified band. General ANOVA, $F=3.15, p<0.05$. Duncan's test, $C G$ versus ICG, SCG, CUG, and N, ${ }^{*} p<0.05$. N of each group is indicated in the respective bar.

killed 45 min after the last session. A third group, the shockedcontrol group (SCG), was exposed to both contexts, $3 \mathrm{~h}$ apart, over $6 \mathrm{~d}$. On the seventh day, they were shocked in the new context and killed 45 min later. A fourth group, the context unshocked group (CUG), was exposed to both contexts, $3 \mathrm{~h}$ apart, over $7 \mathrm{~d}$. They were also killed $45 \mathrm{~min}$ after the final trial (Fig. 7A). A naive group was also included ( $N$ group). In Figure $7 B$, the densitometric analyses of the gel shift (Fig. 7C) of the different samples are shown. Only the CG group showed significantly higher levels of activity with respect to the other groups (general ANOVA, $F_{(4,44)}=3.15, p<0.05$; Duncan's test, CG vs ICG, SCG, $\mathrm{CUG}$, and $\mathrm{N}, p<0.05)$. This result supports the hypothesis that the activation of NF- $\kappa \mathrm{B}$ in hippocampus is part of the plasticity mechanism required for long-term storage of the CS-US association. The fact that NF- $\kappa \mathrm{B}$ was not activated in groups ICG and SCG indicates that the shock per se does not activate NF- $\kappa \mathrm{B}$ unspecifically. The lack of activation observed in the CUG group indicates that, after repeated presentation of the context, no additional plasticity mechanisms are required for contextual information processing in hippocampus.

\section{Presence of Decoy in hippocampus 15 min after administration inhibits NF- $\kappa \mathrm{B}$}

To confirm that the oligonucleotide DNAs used in our experiments were present in hippocampal neurons within the time window necessary to inhibit retrieval-induced NF- $\kappa$ B activation, we performed intrahippocampal injections of fluoresceinated De- 
A
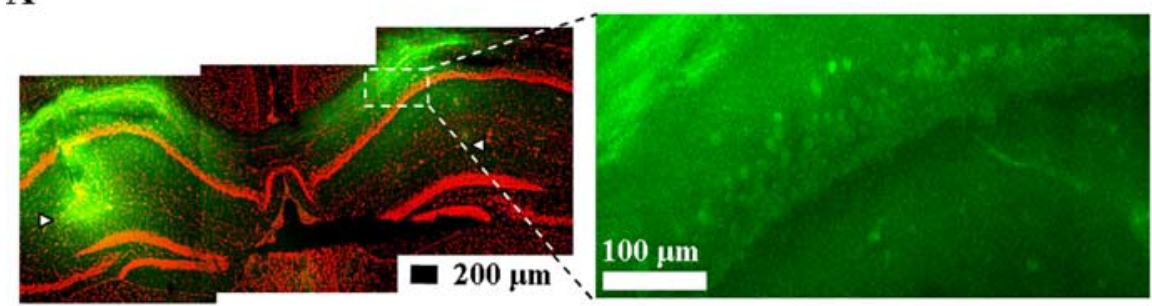

B

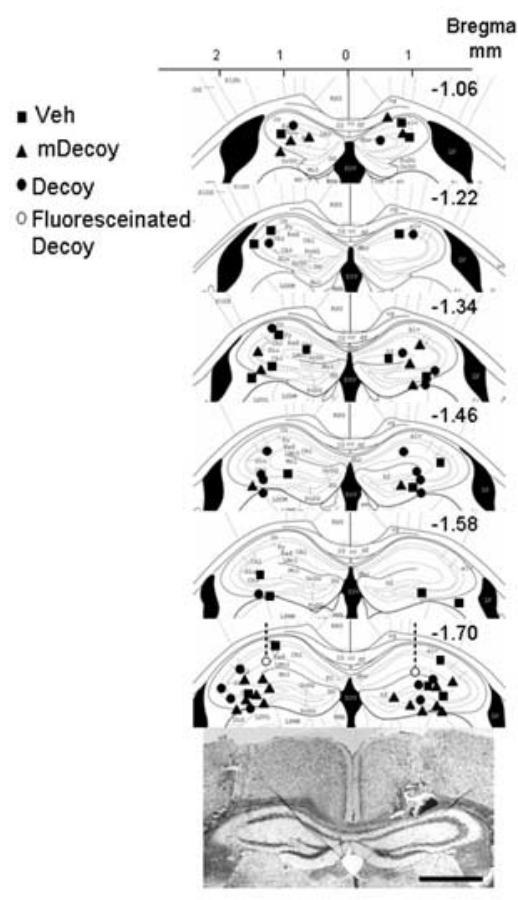

D

C

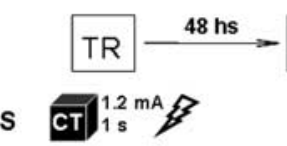

T1
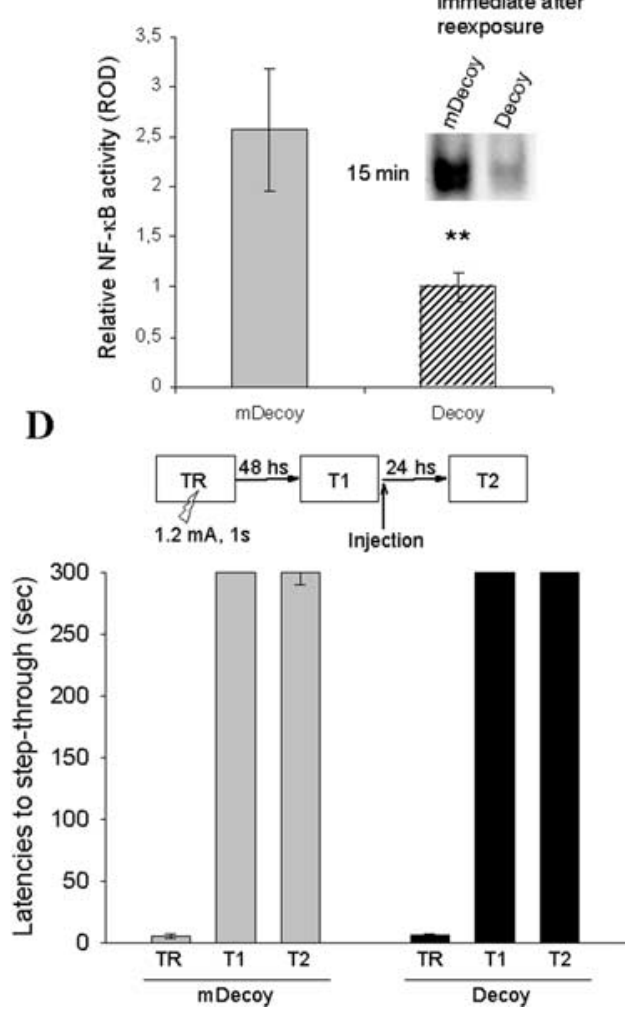

Figure 8. Presence of Decoy in hippocampus inhibits NF- $\kappa$ B activity. $\boldsymbol{A}$, Confocal micrographs show localization of the fluoresceinated Decoy (green) 15 min after injection. Costained with propidium iodide (red). The arrowheads show the deepest position of the needle. $\boldsymbol{B}$, Coronal brain image is adapted from the atlas of Franklin and Paxinos (2001), indicating with dashed lines and black squares the position of the injection in the hippocampus. The last coronal section (Nissl stained) shows the trace of the needle. $\boldsymbol{C}$, Top diagram, Design of the experiment for shocked groups receiving either mDecoy or Decoy intrahippocampal injection immediately after reexposure. TR, Training with a footshock; $\mathrm{T1}$, reactivation session. Animals were killed $15 \mathrm{~min}$ after T1. The graph represents NF- $\kappa$ B activity relative to the Decoy group mean value $15 \mathrm{~min}$ after injection of mDecoy or Decoy. ANOVA, $F_{(1,10)}=11.36, p<0.01$. Duncan's test, mDecoy versus Decoy, ${ }^{* *} p<0.01 ; N=5$ and 7 , respectively. Inset, Representative EMSAs of the two groups. D, Administration of mDecoy or Decoy in the forelimb primary somatosensory cortex after reexposure, shows no effect on retention. The top diagram is as in $C$. Graph, Each bar represents the medians and interquartile ranges. Mice were injected either with mDecoy $(N=9)$ or Decoy $(N=9)$.

coy. Fifteen minutes after the injection, the presence of fluorescence in neurons was confirmed by confocal microscopy (Fig. $8 A$ ). The same analysis was performed $45 \mathrm{~min}$ after injection (data not shown). In this case, we observed a more extensive area of fluorescence. We used histological analysis to determine the position of the needle tip during injection. As a representative sample for all injections, we inspected animals that were part of two of the Decoy experiments. The result is displayed in Figure $8 B$. In addition, two groups of animals were trained, tested at $48 \mathrm{~h}$, and received intrahippocampal injections of mDecoy or Decoy immediately after T1. Both groups showed retention at

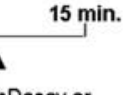

cT mDecoy or Decoy injection reexposure

testing (data not shown). The NF- $\kappa \mathrm{B}$ activity 15 min after memory reactivation was significantly reduced in animals injected with Decoy when compared with animals injected with mDecoy (Fig. $8 C$ ) (ANOVA, $\left.F_{(1,10)}=11.36, p<0.01\right)$. These results indicate that Decoy is able to reach the cellular soma in hippocampus and inhibit NF- $\kappa$ B within 15 min after injection. Furthermore, we performed an anatomical control experiment in which animals were injected post-T1 with Decoy or mDecoy in the primary somatosensory cortex, forelimb region. In this experiment, no memory impairment was found (Fig. $8 D$ ), supporting the site-specific effect of Decoy hippocampal infusion.

\section{Discussion}

The experiments presented here support the hypothesis that NF- $\kappa \mathrm{B}$ transcription factor is activated in hippocampus by retrieval, and that this activation is involved in memory restabilization. Retrieval has been induced $48 \mathrm{~h}$ after a one-trial inhibitory avoidance task by reexposure of the animals to the training context. NF- $\kappa \mathrm{B}$ inhibition in hippocampus, achieved by two independent strategies, impairs long-term memory only when applied immediately after retrieval. This effect does not occur $3 \mathrm{~h}$ later, indicating a transient time window of memory vulnerability. Such early window of drug effect correlates well with the peak of NF- $\kappa$ B activation at $15 \mathrm{~min}$ after reexposure. We observed the effect of NF- $\kappa \mathrm{B}$ inhibition only after a long period of time $(24 \mathrm{~h}$ or more). Shortly after treatment ( $3 \mathrm{~h})$, the effect was absent. This impairment persists for $>3$ weeks. Although the nature of such impairment is unclear, the absence of spontaneous recovery of the amnesic effect over such extended period, suggests that there is a disruption of the memory trace rather than a retrieval deficit. The NF- $\kappa$ B inhibition effect was not observed when reexposure to the training context was omitted, indicating that retrieval is necessary to open the lability period after memory reactivation. These results implicate an effect of NF- $\kappa$ B inhibition on memory reconsolidation.

Interestingly, we found that retrieval induced NF- $\kappa$ B activation in hippocampus exhibits a different profile than that observed in consolidation. During consolidation, an initial inhibition $15 \mathrm{~min}$ after training was found, followed by activation $45 \mathrm{~min}$ after and a return to basal levels at 120 min (Freudenthal et al., 2005). In contrast, during reconsolidation, we found NF- $\kappa \mathrm{B}$ activation 15 min after retrieval, rather than inhibition. Finally, 45 min after reactivation treatment, no activation was found. These data suggest that NF- $\kappa$ B activation occurs earlier in memory reconsolidation than in memory consolidation. The results of the present paper, together with a previous work in crabs (Merlo et al., 2005), 
support the idea that NF- $\kappa \mathrm{B}$ regulation of gene expression is a conserved mechanism required for memory reconsolidation. In the crab study, the reexposure to the training context also induced a faster NF- $\kappa \mathrm{B}$ activation than after training. Its inhibition also impairs long-term but not short-term memory. Additional differences in the temporal requirements for consolidation and reconsolidation are described in other models (for review, see Alberini, 2005). The faster activation in the reconsolidation process suggests that molecular pathways leading to NF- $\kappa \mathrm{B}$ nuclear translocation and DNA binding activity are facilitated by training. This facilitation could persist for at least $2 \mathrm{~d}$, allowing a faster NF- $\kappa \mathrm{B}$ response in retrieval. In fact, the peak of activation in reconsolidation seems to be not only faster, but also higher and more coherent in time than in consolidation (Freudenthal et al., 2005).

The dorsal hippocampus has formerly been implicated in the retrieval of contextual memories (Matus-Amat et al., 2004). Here, we present evidence that retrieval induces $\mathrm{NF}-\kappa \mathrm{B}-$ dependent neural plasticity in hippocampus, which is required for long-term memory restabilization. These data shed light on how information is processed and which brain areas are involved in the distinct phases of memory storage, establishing a correlation between specific molecular events and the behavioral readout (Miller and Sweatt, 2006).

As in our previous work studying NF- $\kappa \mathrm{B}$ in hippocampus during consolidation (Freudenthal et al., 2005), shocked and unshocked animals showed a similar activation profile. The shocked animals groups in the experiments of Figures 6 and 7 indicate that both the new context and the association of this context with a shock, induced NF- $\kappa \mathrm{B}$ activation. If we consider NF- $\kappa \mathrm{B}$ activation as a marker of long-lasting neural plasticity, this result suggests that the hippocampal formation is involved in linking the US to the context information that is part of the CS. Fear conditioning experiments have also implicated the hippocampus in context-shock association (Moita et al., 2003).

Other inhibitory avoidance experiments in rats found that $\mathrm{C} / \mathrm{EBP}$ transcription factor is required in the hippocampus after training, but it is not required after retrieval (Tronel et al., 2005). Here, we showed that the activity of another transcription factor, NF- $\kappa \mathrm{B}$, is required in both consolidation and reconsolidation. Aside from differences in species and task, these differences may be ascribed to the fact that different transcription factors play differential roles during memory restabilization. In agreement with the hypothesis of differential roles of the gene transcription mechanisms, Zif268 transcription factor is involved in reconsolidation but not in consolidation of fear memory (Lee et al., 2004). We propose that fast and central pathways of gene expression regulation, like CREB and NF $-\kappa \mathrm{B}$, are involved in all processes of synaptic plasticity. The second round of transcription, regulated by immediate-early gene induction, is finely tuned depending on the neuronal pathways and brain regions involved.

It is worth noting that, within our experimental conditions, several different pharmacological (Boccia et al., 2004, 2006) and nonpharmacological manipulations (Boccia et al., 2005) impaired memory reconsolidation and did not show spontaneous recovery. These results are in complete accordance with the present findings.

An increasing body of experimental data supports the hypothesis that the NF- $\kappa \mathrm{B}$ transcription factor plays an important role in neural plasticity required for long-lasting memory storage. Our results extend the function of $\mathrm{NF}-\kappa \mathrm{B}$ to memory reactivation after retrieval.
Note added in proof. In a very recent publication, Lubin and Sweatt (2007) provided further evidence of a role for the NF- $\kappa$ B pathway in memory reconsolidation.

\section{References}

Alberini CM (2005) Mechanisms of memory stabilization: are consolidation and reconsolidation similar or distinct processes? Trends Neurosci 28:51-56.

Blanchard RJ, Fukunaga, KK, Blanchard, DC (1976) Environmental control of defensive reaction to footshock. Bull Psychon Soc 8:129-130.

Boccia MM, Acosta GB, Blake MG, Baratti CM (2004) Memory consolidation and reconsolidation of an inhibitory avoidance response in mice: effects of i.c.v. injections of hemicholinium-3. Neurosci 124:735-741.

Boccia MM, Blake MG, Acosta GB, Baratti CM (2005) Memory consolidation and reconsolidation of an inhibitory avoidance task in mice: effects of a new different learning task. Neuroscience 135:19-29.

Boccia MM, Blake MG, Acosta GB, Baratti CM (2006) Post-retrieval effects of i.c.v. infusions of hemicholinium in mice are dependent on the age of the original memory. Learn Mem 13:376-381.

Bozon B, Davis S, Laroche S (2003) A requirement for the immediate early gene zif268 in reconsolidation of recognition memory after retrieval. Neuron 40:695-701.

Davis HP, Squire LR (1984) Protein synthesis and memory: a review. Psychol Bull 96:518-559.

Debiec J, LeDoux JE, Nader K (2002) Cellular and systems reconsolidation in the hippocampus. Neuron 36:527-538.

Fanselow MS (1986) Associative vs topographical accounts of the immediate shock-freezing deficit in rats: implication for the response selection rules governing species-specific defensive reactions. Learn Motiv 17:16-39.

Fanselow MS (1990) Factors governing one-trial contextual conditioning. Anim Learn Behav 18:264-270.

Fanselow MS, Gale GD (2003) The amygdala, fear, and memory. Ann NY Acad Sci 985:125-134.

Franklin KBJ, Paxinos G (2001) The mouse brain in stereotaxic coordinates. London: Academic.

Freudenthal R, Romano A, Routtenberg A (2004) Activation of the transcription factor NF- $\kappa$ B after in vivo perforant path LTP in the mouse hippocampus. Hippocampus 14:677-683.

Freudenthal R, Boccia MM, Acosta GB, Blake MG, Merlo E, Baratti CM, Romano A (2005) NF-kappaB transcription factor is required for inhibitory avoidance long-term memory in mice. Eur J Neurosci 21:2845-2852.

Ghosh S, Karin M (2002) Missing pieces in the NF-kappaB puzzle. Cell 109 [Suppl]:S81-S96.

Glowinski J, Iversen LL (1966) Regional studies of catecholamines in the rat brain: I. The disposition of $[3 \mathrm{H}]$ norepinephrine, $[3 \mathrm{H}]$ dopamine and $[3 \mathrm{H}]$ dopa in various regions of the brain. J Neurochem 13:655-669.

Hall J, Thomas KL, Everitt BJ (2001a) Cellular imaging of zif268 expression in the hippocampus and amygdala during contextual and cued fear memory retrieval: selective activation of hippocampal CA1 neurons during the recall of contextual memories. J Neurosci 21:2186-2193.

Hall J, Thomas KL, Everitt BJ (2001b) Fear memory retrieval induces CREB phosphorylation and Fos expression within the amygdala. Eur J Neurosci 13:1453-1458.

Landeira-Fernandez J, DeCola JP, Kim JJ, Fanselow MS (2006) Immediate shock deficit in fear conditioning: effects of shock manipulations. Behav Neurosci 120:873-879.

Lee JL, Everitt BJ, Thomas KL (2004) Independent cellular processes for hippocampal memory consolidation and reconsolidation. Science 304:839-843

Lubin FD, Sweatt JD (2007) The I $\kappa$ B kinase regulates chromatin structure during reconsolidation of conditioned fear memories. Neuron 55:942957.

Mactutus CF, Riccio, DC, Ferek JM (1979) Retrograde amnesia for old (reactivated) memory: some anomalous characteristics. Science 204:1319-1320.

Matus-Amat P, Higgins EA, Barrientos RM, Rudy JW (2004) The role of the dorsal hippocampus in the acquisition and retrieval of context memory representations. J Neurosci 24:2431-2439.

McGaugh JL, Petrinovich LF (1966) Neural consolidation and electroconvulsive shock reexamined. Psychol Rev 73:382-387. 
Merlo E, Freudenthal R, Romano A (2002) The IkappaB kinase inhibitor sulfasalazine impairs long-term memory in the crab Chasmagnathus. Neuroscience 112:161-172.

Merlo E, Maldonado H, Romano A (2005) Activation of the transcription factor NF-kappaB by retrieval is required for long-term memory reconsolidation. Learn Mem 12:23-29.

Miller CA, Sweatt JD (2006) Amnesia or retrieval deficit? Implications of a molecular approach to the question of reconsolidation. Learn Mem 13:498-505.

Misanin JR, Miller RR, Lewis DJ (1968) Retrograde amnesia produced by electroconvulsive shock following reactivation of a consolidated memory trace. Science 16:554-555.

Moita MA, Rosis S, Zhou Y, LeDoux JE, Blair HT (2003) Hippocampal place cells acquire location-specific responses to the conditioned stimulus during auditory fear conditioning. Neuron 37:485-497.

Nader K, Schafe GE, LeDoux JE (2000) Fear memories require protein synthesis in the amygdala for reconsolidation after retrieval. Nature 406:722-726.

Pedreira ME, Pérez-Cuesta LM, Maldonado H (2002) Reactivation and reconsolidation of long-term memory in the crab Chasmagnathus: protein synthesis requirement and mediation by NMDA-type glutamatergic receptors. J Neurosci 22:8305-8311.
Romano A, Freudenthal R, Merlo E, Routtenberg A (2006) Evolutionaryconserved role of the NF- $\kappa \mathrm{B}$ transcription factor in neural plasticity and memory. Eur J Neurosci 24:1507-1516.

Rossato JI, Bevilaqua LR, Medina JH, Izquierdo I, Cammarota M (2006) Retrieval induces hippocampal-dependent reconsolidation of spatial memory. Learn Mem 13:431-440.

Sara SJ (2000) Retrieval and reconsolidation: toward a neurobiology of remembering. Learn Mem 7:73-84.

Siegel S (1956) Non-parametric statistics for the behavioural science. New York: McGraw-Hill.

Taubenfeld SM, Milekic MH, Monti B, Alberini CM (2001) The consolidation of new but not reactivated memory requires hippocampal C/EBPbeta. Nat Neurosci 4:813-818.

Tronel S, Milekic MH, Alberini CM (2005) Linking new information to a reactivated memory requires consolidation and not reconsolidation mechanisms. PLoS Biol 3:e293.

Weber CK, Liptay S, Wirth T, Adler G, Schmid RM (2000) Suppression of NF-kappaB activity by sulfasalazine is mediated by direct inhibition of IkappaB kinases alpha and beta. Gastroenterology 119:1209-1218.

Yin M-J, Yamamoto Y, Gaynor RB (1998) The anti-inflammatory agents aspirin and salicylate inhibit the activity of IkappaB kinase-beta. Nature 396:77-80. 